\title{
Large-scale Isolation, Expansion and Characterization of Human Amniotic Epithelial Cells
}

\author{
Sanjay Gottipamula, K. N Sridhar
}

Sri Research for Tissue Engineering Pvt. Ltd, Shankara Research Centre, Rangadore Memorial Hospital, Bangalore, India

Background and Objectives: The human Amniotic epithelial cells (AME) derived from amniotic membrane of placenta have been considered as the potential fetal stem cell source with minimal or no ethical concerns and are important therapeutic tool for anti-fibrotic and regenerative therapies.

Methods and Results: Here, we evaluated the isolation, media screening, scale-up and characterization of AME cells. The isolation, expansion of AMEs were performed by sequential passaging and growth kinetics studies. The AMEs were characterized using immunocytochemistry, immunophenotyping, In-vitro differentiation, and anti-fibrotic assays. The growth kinetics study revealed that the AME cultured in Ultraculture (UC) and DMEM knockout (DMEM-KO) have prominently higher growth rate compared to others. Overall, the AMEs cultured from 5 different media retained basic morphological characteristics and the functional characteristics.

Conclusions: Our result suggests that the AMEs can be successfully cultured in UC based complete media without losing its epithelial cell characteristics even after passaging for passage 2 (P2). However, a careful and methodical pre-clinical and clinical translation studies need to be conducted to show its safety and efficacy.

Keywords: Amniotic epithelial cells, Cell therapy, Cryopreservation, Stability, Growth kinetics, Tissue engineering

\section{Introduction}

Regenerative medicine has been revolutionized by the transformation of clinician led cell therapeutic procedures and attained the landmark of billion dollar global revenues with unlimited potential (1). Epithelial cells have been proven as promising cell therapeutic agent in most advanced wound care products like kaloderm (cultured al-

Received: January 13, 2018, Revised: February 13, 2018, Accepted: April 3, 2018, Published online: April 30, 2018 Correspondence to K. N Sridhar

Sri Research for Tissue Engineering Pvt. Ltd, Shankara Research Centre, Rangadore Memorial Hospital, Bangalore, India

Tel: +91-080-41076759

E-mail: knsridhar@sr-te.com

(c) This is an open-access article distributed under the terms of the Creative Commons Attribution Non-Commercial License (http://creativecommons.org/ licenses/by-nc/4.0/), which permits unrestricted non-commercial use, distribution, and reproduction in any medium, provided the original work is properly cited.

Copyright (c) 2018 by the Korean Society for Stem Cell Research logeneic infants foreskin), Permaderm $^{\mathrm{TM}}$, Apligraf $^{\mathrm{TM}}$, $\mathrm{OrCel}^{\mathrm{TM}}$ (2-5). The current limitation of these commercially available skin substitutes includes cell sourcing from various donors, of invasive procedures, ethical issues, a time-consuming manufacturing process of about 2 3 weeks and high cost (6). Further, sourcing of small biopsy sample from healthy donor gradually increases the extended culturing and passages to meet the clinical trial demands and for the preparation of donor cell banks in case of allogeneic purpose. Such practices require frequent infectious diseases screening of various donors for cell sourcing's, tedious small-scale isolation procedures and multi-stage expansion and cryopreservation procedures. Therefore epithelial cells sourcing from amniotic membrane not only forms an alternative for adult keratinocytes but also has various clinical applications like fibrotic, chronic inflammatory and age related diseases (7-10).

The human Amniotic Epithelial cells (AMEs) isolated from the amniotic membrane of the discarded placenta is a potential non-controversial stem cell source. AMEs have 
an ability to differentiate all three germ layers and possess the pluripotent stem cells characteristics (11). Thus considered as evolving therapeutic tool for development of various clinical applications. The AMEs are flat cuboidal epithelial cells, plastic adherent, expandable stromal cells and have profound anti-fibrotic, anti-inflammatory, non-tumorigenicity and low antigenicity (12-14). Besides, AMEs secretes a variety of cytokines factors, extracellular matrix (ECM) depending upon the microenvironment at the implanted site and this intrinsic therapeutic property allows its possible applications (15). Furthermore, AMEs have its economic advantage over other biological cell sourcing because of its availability, little ethical concerns, ease of isolation and expansion. All these ethical, technical and economic advantages of AMEs increase its potential as a cell therapeutic intermediate in cell therapy as well as in tissue engineering applications. Such AMEs require dynamic isolation procedures, media optimization and clinical scale production systems with adequate testing on quality and functional properties.

The media optimization procedures for AMEs is to provide maximum chances of productivity in the terms of cell yield and functionality. Secondly, several media have been used for the culture of AMEs. But still, there is no direct comparison of the effect of SCM (serum containing media) and SFM (serum free media) on the AMEs of the same batch. Hence, in the present study, we have studied the dynamic isolation for large-scale isolation and media optimization studies of AME. We have compared cell yield, morphological characteristics and growth kinetics of AMEs cultured in 5 different cell culture media as DMEM-HG (DM) DMEEM-KO (KO), Ultra culture (UC), Epilife (Epi) and KOSR media.

\section{Materials and Methods}

\section{Placenta collection}

The ethics committee of the Rangadore memorial hospital approved the collection process of placenta from voluntary donors through signed informed consent from the mother. The placenta from healthy mother undergoing elective cesarean deliveries were utilized. Exclusion of placenta including patient positive testing for human immunodeficiency virus, Hepatitis B virus, Hepatitis C virus, tuberculosis, Chlamydia trachomatis, Neisseria gonorrhoeae, Syphilis or any macroscopic abnormal placenta.

\section{Placenta processing}

The Human placenta samples were processing aseptically in a biological safety cabinet of class 10,000 clean room area. The isolation of amnion layer and cells from placenta was done as previously described by Miki et al., with the following changes (16). The amnion layer was mechanically peeled-off from chorion layer and weight of amnion was recorded before washing two times with saline followed by one time with phosphate-buffered saline without calcium and magnesium (DPBS) to remove blood. The amniotic membrane samples were cut to get the multiple pieces of $5 \times 5 \mathrm{~cm}$ with a scalpel blade and then these pieces were transferred to $10 \times$ Anti-Anti $^{\mathrm{TM}}$ antibiotics solution for $20 \mathrm{~min}$ at $37^{\circ} \mathrm{C}$ orbital shaker at $64 \mathrm{rpm}$. The primary digestion wash was carried out by diluting the 0.25\% Trypsin (Gibco, Grand Island, NY, http://www. invitrogen.com) to get $0.012 \%$ of $200 \mathrm{ml}$ and incubated in an orbital shaker incubator at $37^{\circ} \mathrm{C}$ of $64 \mathrm{rpm}$ for $10 \mathrm{mi}$ nutes of digestion to remove debris etc. The cells from second and third digestion at each 40 minutes digestion at $64 \mathrm{rpm}$ were pooled in complete media. The viability and total cell number of AME cells were determined by dye exclusion of trypan blue with a hemocytometer.

\section{Media screening and isolation}

The isolated cells were resuspended in five different culture media; 1) DMEM-HG (DMEM) 2) DMEM-KO and 3) Ultra-culture (UC). The $1^{\text {st }}, 2^{\text {nd }}$, and $3^{\text {rd }}$ media were supplemented with $10 \%$ (v/v) FBS, $2 \mathrm{mM}$ Glutamax (Invitrogen) and Pen-Strep (Invitrogen). 4) Epi-life complete media: The T-25 flasks were coated with coating matrix $\mathrm{kit}^{\mathrm{TM}}$ (Life Technologies) as per the manufacturer's instruction; EpiLife complete medium (EpM) was prepared by adding S7 supplements (Life Technologies) and Epilife basal media (Life Technologies) for serum free and xeno free cultures as per manufacturer's instruction. 5) Knock-out serum replacement supplement (KOSR) media: The KOSR supplements (10\%) were added in DMEM-KO basal media containing $2 \mathrm{mM}$ and Glutamax (Invitrogen) and Pen-strep (Invitrogen). All the above media supplemented with $10 \mathrm{ng} / \mathrm{ml}$ EGF (Sigma).

The isolated AME single cell suspension was seeded in pre-coated T 25 flask for Epilife complete media, KOSR complete media, DMEM-KO, DMEM, and UC at a seeding density of 50,000 cells $/ \mathrm{cm}^{2}$ at passage $0(\mathrm{P} 0)$. The $\mathrm{AME}$ cells seeded in five different culture media were incubated at $37^{\circ} \mathrm{C}$, in a humidified $5 \% \mathrm{CO}_{2}$ incubator. During the culture process, the media were exchanged with freshly prepared respective culture media for every $48 \mathrm{~h}$ until it completes 5 media changes or $80 \sim 90 \%$ confluence. The $\mathrm{AME}$ cells were dissociated from the culture vessels by digestion for $3 \sim 5 \mathrm{~min}$ at $37^{\circ} \mathrm{C}$ with TryPLE Express - 1X (Life Technologies). The morphological observations during 
cultivation were captured by phase contrast microscopy. All the experiments were performed in triplicate.

\section{Sub culturing of AME cells}

The $\mathrm{P} 0$ - harvested AMEs were passaged in respective culture media till P2 by seeding at a density of 20,000 cells per $\mathrm{cm}^{2}$. The cells were screened every day and media change was done at around $50 \%$ confluency and harvested for further passages at around 80 90\% confluency.

\section{Growth kinetics and Large-scale expansion}

Population doubling time (PDT) of AMEs cultured in 5 different media were calculated. Cumulative population doublings (CPD) were calculated by sequential sub-culturing from P0 to P2 and harvested at $80 \sim 90 \%$ confluency in each passage. The AME cells cultured in UC media were cultured in one CellSTACKS and two CellSTACKS at P0 and P1 and were used to study the growth kinetics.

\section{Immunocytochemistry and immunophenotyping}

The immunocytochemistry (ICC) of cultured cells of five different culture media at P1 were assessed for identification of epithelial cell markers like pan cytokeratin (AE1/AE3). The immnostaining of AE1/AE3markers (Biogenex kit) was done as per manufacturer's instructions. Briefly, after avidin-biotin blocking solution, the smear was painted with primary antibody for overnight at $4^{\circ} \mathrm{C}$ and biotinylated secondary antibody were incubated for 30 min. Microscopic observation was carried out by Haematoxylin \& Eosin (H\&E) staining after DAB stain.

Quantitative expression profile of EpCAM and Cytokeratin $(3,5,6,10,13 \& 18)$ as Cyto of uncultured PrePO and cultured cells of AME from 5 different media were analysed by flow cytometry. The triplicates of AMEs derived from 5 different media at passage 1 were used. The harvested cells were washed and adjusted to a concentration of $1 \times 10^{6}$ cells $/ \mathrm{ml}$ in PBS solution. Cells were painted with $0.1 \sim 10 \mu \mathrm{g} / \mathrm{ml}$ of respective primary antibody (Phycoerythrin -PE/FITC, Abcam) in the polystyrene round bottom $12 \times 75 \mathrm{~mm}^{2}$ Falcon tubes and were incubated for 30 minutes at room temperature. Isotypes as negative controls were run in parallel by omitting the primary antibody at the same concentration as test samples. The cells were analysed on a flow cytometer (Beckman Coulter, FC500 series). Thirty thousand events were acquired per sample, and side and forwarded scatter gates were set to exclude dead cells, debris using unstained cells. Isotypes followed by testing samples were run and analyzed. The following markers were analyzed: Cyto-FITC and EPCAM-PE, (Abcam, USA).

\section{In vitro differentiation}

The AME cells at P1 were seeded at a density of 20,000 $(20 \mathrm{~K})$ cells $/ \mathrm{cm}^{2}$ in six-well culture dishes and respective induction media were changed once it reaches $70 \sim 80 \%$ confluent. To induce osteoblast differentiation of AME at P1 Stempro Osteogenesis differentiation medium (Invitrogen) was used as per manufacturer's instructions. Briefly, the osteogenesis media was changed every 2 days and maintained the culture until day 14 to 21 days. Stained with Alizarin Red (Sigma) to monitor the mineralization of Osteoblasts. Similarly, Adipogenic differentiation and chondrogenic differentiation (Invitrogen) were induced with respective induction medium as per manufacturing instructions. Media change were done with respective differentiation media on alternative day. The culture plate was stained with Oil Red O (Sigma) for presences of adipocytes. The safranine O staining solution was added to chondrogenic differentiated culture plates and images were captured after rinsing with distilled water.

\section{Myogenic differentiation}

The 20,000 cells each were seeded on the cover slips for two days to get confluency and then subjected to Myogenic differentiation media for 21 days with intermittent media change at every 3 days. Myogenic differentiation medium consists of DMEM-KO (Life Technologies), 2 mM L-Glutamax (Life Technologies), 0.5\% Antibiotic-Antimycotic solution (Life Technologies), $5 \mathrm{ng} / \mathrm{ml}$ human recombinant PDGF-AB (Shenandoah Biotechnology), 5 ng/ml TGF- $\beta 1$ (R\&D Systems), $30 \mu \mathrm{mol} / \mathrm{L}$ L-ascorbic acid (Sigma-Aldrich) and 10\% FBS (Hyclone). The smear was washed in DPBST for $10 \mathrm{~min}$ after fixing in cold methanol, acetone for 10 min. These were then subjected to immunostaining of Desmin markers (Biogenex kit) as per manufacturer's instructions. Microscopic observation was carried out by Haematoxylin \& Eosin (H\&E) staining after DAB stain.

\section{Fibroblast suppression assay by spent media}

The buccal mucosal biopsy samples were taken from the donors of impacted wisdom tooth extraction. Informed consents were obtained after the approval of institutional ethics committee. The primary fibroblast derived from buccal submucosa were isolated and maintained in DMEM - HG (High Glucose) supplemented with 10\% FBS (Hyclone), 1X Antibiotic and Antimycotic in tissue culture flasks and incubated at $37^{\circ} \mathrm{C}$ and $5 \% \mathrm{CO}_{2}$. The fibroblasts at P2 was used to seed in multiples of 96 well plate at $25000(25 \mathrm{~K})$ each and $50 \mathrm{~K}$ cells per well and allowed to attach overnight. The already collected conditioned media from fibroblast (control), AME (Test-I) and BME 
(Test-II) were added to respective 96 well plates (triplicate) and maintained for $24 \mathrm{~h}$. The cell proliferation was assessed using a 3-(4,5-dimethyl-thiazol-2-thiazolyl)-2,5-diphenyl-2H-tetrazolium bromide (MTT) assay. The absorbance at $570 \mathrm{~nm}$ was measured using microplate reader. Each experiment were performed three times.

\section{Statistical analysis}

All values were expressed as mean \pm SEM (standard error of mean). Data were analyzed by paired Student's t-test using Graphpad Prism (version 5, Graphpad Software Inc., La Jolla, CA, USA). Student's t-test (2-tailed) was performed to compare means between groups. $p$ value $<0.05$ was considered significant.

\section{Results}

\section{Amnion processing and Isolation}

The placenta samples were received at a manufacturing facility in sterile transportation container at $2 \sim 8^{\circ} \mathrm{C}$. The average number of isolated amniotic epithelial cell yield per gr of amnion of several batches ranged from 9 to 15 million at a viability of $>70 \%$ (Table 1 ). Most of the cells were detached during first and second digestion steps at $\mathrm{rpm}$ of 64 . The further round of digestion and increase

Table 1. Isolation cell yield dynamics with respect weight of amnion

\begin{tabular}{ccc}
\hline Total $(\mathrm{CN}$ in mn) & Viability \% & Wt of AM (g) \\
\hline $99.00 \pm 19.49$ & $91.43 \pm 2.9$ & $9.68 \pm 3.38$ \\
\hline
\end{tabular}

$\mathrm{CN}$ : Cell number; mn: millions; Wt: weight; g: grams; $(\mathrm{n}=7)$.

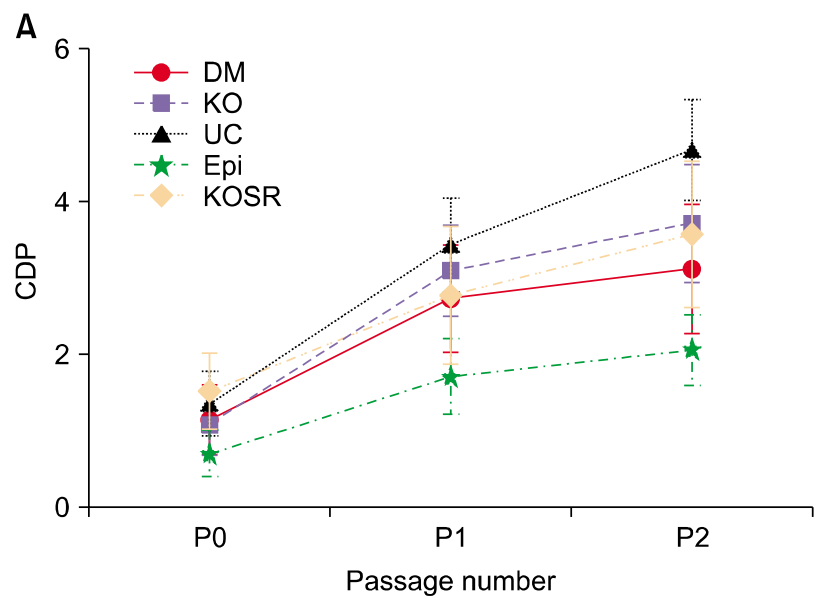

of rpm did not increase the isolation yield, but there was a fall of cell viability, amnion pieces aggregated thereby reduction of surface area exposure for trypsin digestion was noted. The pooled cell suspension from digestion 1 and 2 are passed through 100 -micron cell strainer.

\section{Growth kinetics and large scale expansion}

There is was no distinct growth and morphological pattern in serum containing medium (KO, DM and UC), but AMEs in KOSR had a little slower growth. On the other hand, the AME cultured in EPI media took longer days of culture to get 60 to $70 \%$ confluency.

The passage (P0) cell yield of AMEs from DM, KO, UC, and EPI were prominently higher than AME cells cultured in KOSR (Fig. 1A), but later passages of P1 and P2 AME cultured in serum containing media (DM, KO, UC) showed similar trend of cumulative population doublings (CPDs). In addition, AMEs cultured in serum containing media showed an approximate tight range of population doubling time (PDT) across P0 to P2 (Fig. 1B). It was observed that AMEs cultured in UC media showed prominently higher growth rate as represented by lower PDT across P0 and P1, and slightly higher CPDs. On the other hand, AMEs in CellSTACK Cell culture chamber at $\mathrm{P} 0$ and $\mathrm{P} 1$ of serum containing media has yielded $46.6 \pm 2.8$ million cells over a period of 5 7 days in each passage (Supplementary Table 1). It was clear from the cell yield from small-scale (T-25 flasks) as well as large area flasks like one chambered CellSTACKs have shown similar proliferation rate. However, the proliferation rate decreased from P3 onwards.

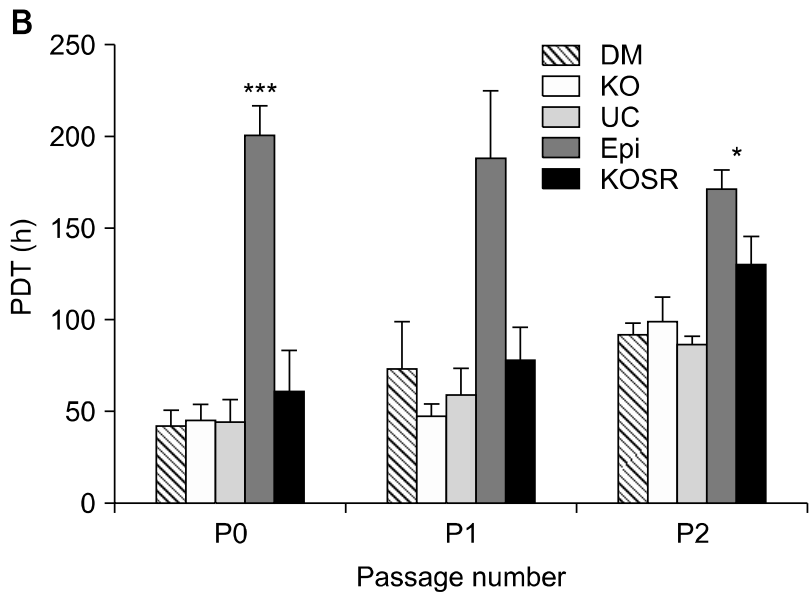

Fig. 1. Growth Kinetics of AME sub cultured in 5 different media. (A) Cumulative population doublings of AMEs plotted against the passage number. (B) Population doubling time of AMEs (Epi is significantly higher $(* * * p<0.001)$ across all passages compared to all other media, except Epi vs KOSR showed $* p<0.05)$. 
A

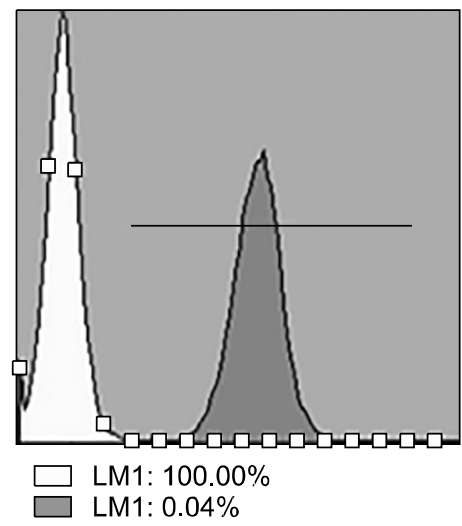

B

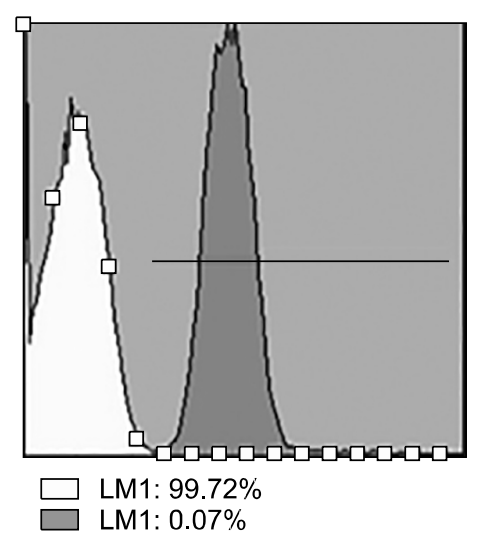

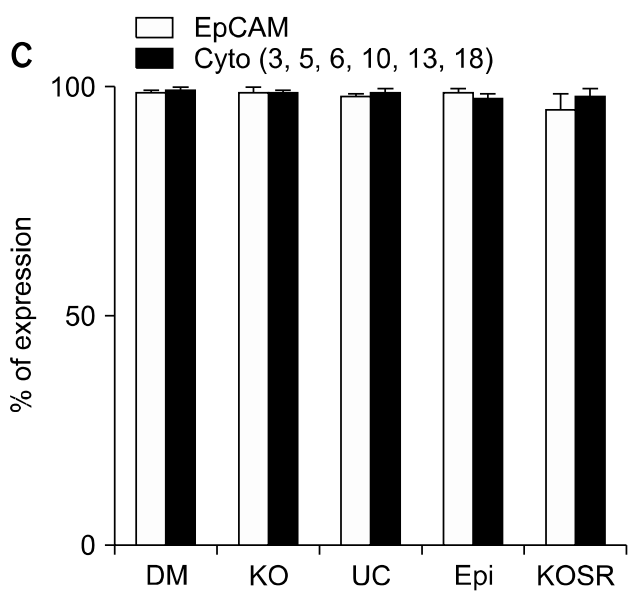

Fig. 2. Immunophenotyping of AME at P1. A representative histogram of isotypes white and grey as EpCAM (A) and Cyto (B) (Cytokeratin $4,5,6,10,13,18)$ of AME cultured in UC respectively. (C) Overall bar chart of Immunophenotyping of EpCAM and cyto expression of AME in all 5 different cell culture media.

\section{Morphological analysis}

The morphological profile of AMEs in serum containing media and serum free media (KO-SR and Epi) shown cobblestone appearances at $80 \sim 90 \%$ Confluency. The rate of attainment of confluency in serum containing media were substantially higher compared to serum free media. The AMEs cultured in UR media attained confluency slightly faster than other cells cultured in other media.

\section{Immunocytochemistry and immunophenotyping}

It was found that the immunophenotype of AME at preP0 of EpCAM and Cyto have differential percentage of expression (Supplementary Fig. 1). AMEs derived from 5 different culture stained positive for anti-pan-cytokeratin (AE1/AE3) demonstrating the epithelial phenotype (Supplementary Fig. 2). Further, the immunophenotyping of AMEs of 5 different culture media showed similar expression of $\mathrm{CD}$ markers profile (Fig. 2A). The $\mathrm{CD}$ marker expression of Anti-cytokeratin was slightly lower in AME cultured in KOSR, Epi compared to others (Fig. 2B).

The AME cells derived from UC media showed prominent higher proliferation rate, lower PDT, slightly smaller morphological features compared to others, and prominently higher $\mathrm{CD}$ marker expression profile of EpCAM and Cytokeratin. Hence AME derived using UC culture media (UC) were further tested for functional characteristics and anti-fibrotic assays.

\section{In vitro differentiation}

The osteogenic differentiation was observed by Alizarin Red staining for calcium deposits (Fig. 3A). The adipo- genic differentiation was not observed by oil red $\mathrm{O}$ staining (Fig. 3B) and were usually characterized by the fatty lipid vacuoles. The chondrogenic differentiation was identified by Safranin O staining after induction with chondrogenic medium for 15 days. Overall, AMEs cultured in UC showed differentiation abilities as evident by their staining properties.

\section{Myogenic differentiation}

Morphologically, myogenic differentiated cells of AME were identified as long multinucleated cells as precursors of myotubes at day 18 to 21. Further the myogenic lineage of AME cells were identified by desmin staining (Fig. 3G $\& \mathrm{H})$.

\section{Anti-fibrotic assay through MTT}

The average fibroblast inhibition in AME conditioned media was about $21 \%$, whereas in BME conditioned media was $16 \%$ (Fig. 4). Although, there were no prominent differences in cell dose dependent inhibition.

\section{Discussion}

Recent advances in cell therapeutics have gained much attention for the clinical evaluation of AMEs, as there are little ethical concerns, religious consideration, legislative regulations and perhaps has unlimited cell source $(16,17)$. AME has generated great interest as human perinatal stem cells derived from neonatal tissue in the promising field of regenerative medicine, and has less age-acquired DNA damage (18). Further, AME can be separated and 

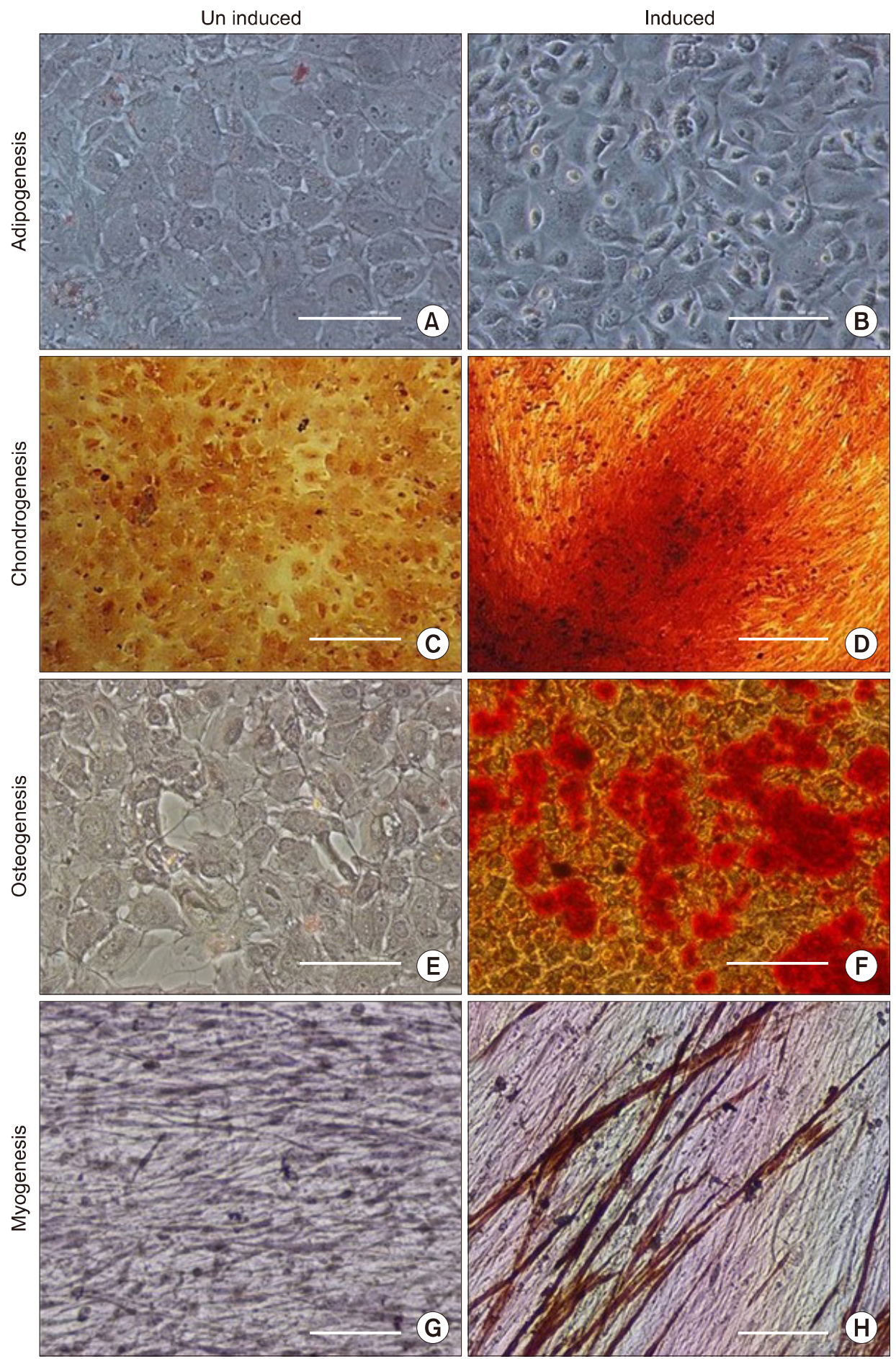

Fig. 3. In-vitro differentiation of AME: (A, $C, E)$ and $(G)$ are un-induced AME as controls and (B, D, F) and $(\mathrm{H})$ are induced with respective induction media. Scale bar -100 microns.

scaled-up for a large number of homogenous single population of cells for the development of the clinical application. The clinical-grade production of these therapeutic cells can be achieved through proper standardization of isolation, expansion and cryopreservation procedures. In this study, we have successfully isolated and cultured the AME in five different culture media. Further, these cells were expanded and characterized and compared in terms of morphological characteristics, growth kinetics, AE1/AE3 and phenotypic profiles. The amicable scalable AME cell source and process development of AMEs towards clinical manufacturing increase its 


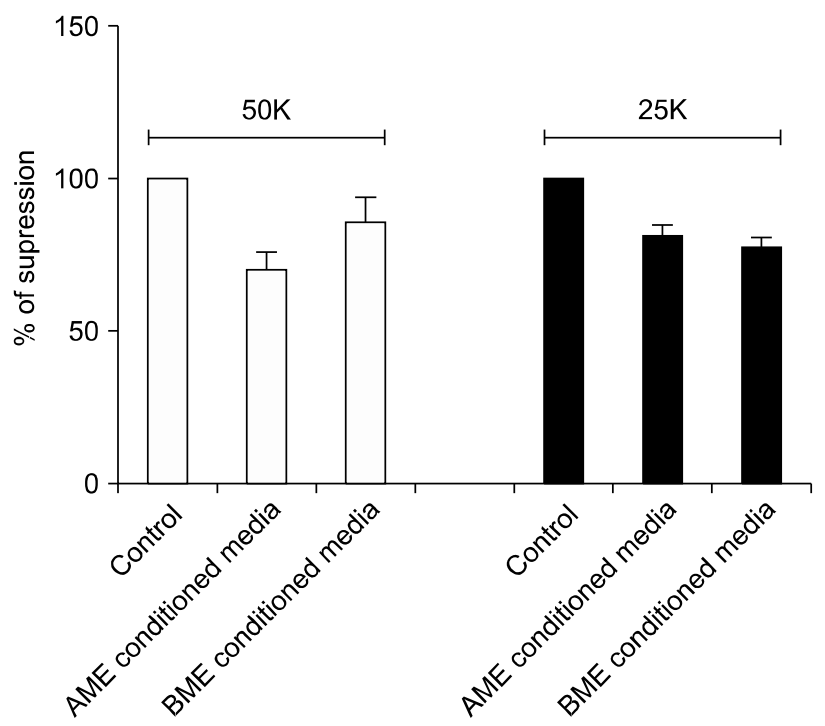

Fig. 4. Conditioned media mediated fibroblast inhibition assay: Conditioned media of AME, BME and controls were added to fibroblast culture and incubated for $24 \mathrm{~h}$ before the proliferation was assessed via MTT assay. Both AME and BME conditioned media are able to inhibit the fibroblast proliferation at two different cell dose of $50 \mathrm{~K}$ and $25 \mathrm{~K}$. Data are normalized to mean proliferation of fibroblast alone as $100 \%(n=3$, pooled data from 3 separate experiments).

usability for development and testing of AMEs in various clinical indications.

The cell yield from dynamic isolation procedure of AME was 80 to 118 million cells with a viability greater than $70 \%$. On the contrary, Miki et al., found higher cell yield of about 80 to 300 million cells and in many cases initial viability of about $75 \%(16,19)$. The differences may be due to the biological variation of the placenta as well as humans across various geographic regions (developed and under developed countries). In our lab, when we followed the protocol of the Miki et al. the cell yield was lower than reported (19). Hence, we re-optimized the isolation protocol with slight variation in volume and trypsin concentration to get above range.

To our knowledge, this is the first report on screening of 5 different cell culture media and accessing its characteristics and in-vitro efficacy studies. The isolated AMEs were cultured in 5 different cell culture media to ensure the robustness and choice for the selection of culture media as it remains crucial matter for clinical application. The AME cultured in serum free and serum based media conditions maintain and retain their typical basic morphological, phenotypical characteristics as demonstrating its identity as epithelial cells $(19,20)$. However, there is an intrinsic difference in the growth kinetic profile in differ- ent culture media in terms of PDT and CPDs of AMEs. The differences may be due to media specificity as we have used the same batch of AMEs for the screening of cell culture media. Similarly, the Ochsenbein-Kolble et al., showed media screening study in 4 different types of media and has four fold increase in proliferation after 14 days with a population doubling time of 150 210 h (21). In contrast, our results has shown superior proliferation ability of about 10 fold (PDs of 2.47) and PDT of 27 to $33 \mathrm{~h}$ and able reach confluency within $5 \sim 7$ days (Fig. 1B). However, the results are not comparable due to variation in growth media and also the biological variation of the sample itself. Further, we have shown the results in CellSTACKs of two different make (Nunc and Corning) to strengthen the reproducibility of AME (Supplementary Fig. 3).

The majority of studies have confirmed the tri-lineage differentiation potential of AME (22). Several authors have reported that the Adipogenic differentiation assay of AME was assessed by Oil Red O staining (22-24). However, we did not find any adipogenic differentiation potential of AMEs even after adipogenic induction media for 21 days (Fig. 3A\&B). Further, our result is consistent with Díaz-Prado et al., who also showed no adipogenic differentiation of AME (25). The discrepancies in the adipogenesis could be due to varied differentiation potential and transient growth retardation (26). However, AMEs displayed more osteogenic and chondrogenic differentiation capabilities indicating the innate characteristics. Further, the AME exhibit myogenic differentiation potential forming myotubes and were detected by desmin staining (Fig. 3G\&H), as it is one of the known myogenic markers. Illancheran et al. was the first one to report AME differentiation potential towards myogenic lineages (27). Moreover, we have tested myogenic differentiation by demonstrating the structural characteristics like myotubes and Desmin staining.

\section{Conclusion}

The AME cells cultured in UC media showed prominent proliferation ability compared to other media. In addition, AMEs were characterized through basic flow cytometric epithelial markers, In-vitro differentiation assay. With these, we feel that AME may be a promising source of cells for large-scale manufacturing and application for the development of anti-fibrotic and several degenerative diseases. To our knowledge, this might be the first comprehensive comparative study on AMEs cultured in serum and serum-free media conditions. Further investigation is 
needed to show its proof-of-concepts as well as pre-clinical trials to elucidate the safety and efficacy of AMEs.

\section{Acknowledgement}

SRTE is fully supported by Sri Sringeri Sharada Peetam and the authors wish to thank Mr. Sumit K Saraswat, Mr. Ashwin KM and Dr. Vandana Bharadwaj for the help with Flow cytometry and data assembly.

\section{Potential Conflict of Interest}

The authors have no conflicting financial interest.

\section{Supplementary Materials}

Supplementary data including one table and three figures can be found with this article online at http:// pdf.medrang.co.kr/paper/pdf/IJSC/IJSC-11-s18001.pdf.

\section{References}

1. Mason C, Brindley DA, Culme-Seymour EJ, Davie NL. Cell therapy industry: billion dollar global business with unlimited potential. Regen Med 2011;6:265-272

2. You HJ, Han SK. Cell therapy for wound healing. J Korean Med Sci 2014;29:311-319

3. Varkey M, Ding J, Tredget EE. Advances in skin substitutes-potential of tissue engineered skin for facilitating anti-fibrotic healing. J Funct Biomater 2015;6:547-563

4. Dodson BP, Levine AD. Challenges in the translation and commercialization of cell therapies. BMC Biotechnol 2015; $15: 70$

5. Ackermann K, Borgia SL, Korting HC, Mewes KR, Schäfer-Korting M. The Phenion full-thickness skin model for percutaneous absorption testing. Skin Pharmacol Physiol 2010;23:105-112

6. Vig K, Chaudhari A, Tripathi S, Dixit S, Sahu R, Pillai S, Dennis VA, Singh SR. Advances in skin regeneration using tissue engineering. Int J Mol Sci 2017;18:E789 doi: 10.3390/ijms18040789

7. Tan JL, Tan YZ, Muljadi R, Chan ST, Lau SN, Mockler JC, Wallace EM, Lim R. Amnion epithelial cells promote lung repair via lipoxin A4. Stem Cells Transl Med 2017; 6:1085-1095

8. Fanti M, Gramignoli R, Serra M, Cadoni E, Strom SC, Marongiu F. Differentiation of amniotic epithelial cells into various liver cell types and potential therapeutic applications. Placenta 2017;59:139-145

9. Yeager AM, Singer HS, Buck JR, Matalon R, Brennan S, O'Toole SO, Moser HW. A therapeutic trial of amniotic epithelial cell implantation in patients with lysosomal storage diseases. Am J Med Genet 1985;22:347-355

10. Di Germanio C, Bernier $M$, de Cabo R, Barboni B. Amniotic epithelial cells: a new tool to combat aging and age-related diseases? Front Cell Dev Biol 2016;4:135

11. Tamagawa T, Ishiwata I, Saito S. Establishment and characterization of a pluripotent stem cell line derived from human amniotic membranes and initiation of germ layers in vitro. Hum Cell 2004;17:125-130

12. Manuelpillai U, Lourensz D, Vaghiiani V, Tchongue J, Lacey D, Tee JY, Murthi P, Chan J, Hodge A, Sievert W. Human amniotic epithelial cell transplantation induces markers of alternative macrophage activation and reduces established hepatic fibrosis. PLoS One 2012;7:e38631

13. Miki T, Lehmann T, Cai H, Stolz DB, Strom SC. Stem cell characteristics of amniotic epithelial cells. Stem Cells 2005;23:1549-1559

14. McDonald CA, Payne NL, Sun G, Moussa L, Siatskas C, Lim R, Wallace EM, Jenkin G, Bernard CC. Immunosuppressive potential of human amnion epithelial cells in the treatment of experimental autoimmune encephalomyelitis. J Neuroinflammation 2015;12:112

15. Parolini O, Alviano F, Bagnara GP, Bilic G, Bühring HJ, Evangelista $M$, Hennerbichler S, Liu B, Magatti $M$, Mao N, Miki T, Marongiu F, Nakajima H, Nikaido T, Portmann-Lanz CB, Sankar V, Soncini M, Stadler G, Surbek D, Takahashi TA, Redl H, Sakuragawa N, Wolbank S, Zeisberger S, Zisch A, Strom SC. Concise review: isolation and characterization of cells from human term placenta: outcome of the first international Workshop on Placenta Derived Stem Cells. Stem Cells 2008;26:300-311

16. Miki T, Marongiu F, Dorko K, Ellis EC, Strom SC. Isolation of amniotic epithelial stem cells. Curr Protoc Stem Cell Biol 2010;Chapter 1:Unit 1E.3

17. Silini AR, Cargnoni A, Magatti M, Pianta S, Parolini O. The long path of human placenta, and its derivatives, in regenerative medicine. Front Bioeng Biotechnol 2015;3:162

18. Matikainen T, Laine J. Placenta--an alternative source of stem cells. Toxicol Appl Pharmacol 2005;207(2 Suppl):544549

19. Miki T. Amnion-derived stem cells: in quest of clinical applications. Stem Cell Res Ther 2011;2:25

20. Wu Z, Hui G, Lu Y, Liu T, Huang Q, Guo L. Human amniotic epithelial cells express specific markers of nerve cells and migrate along the nerve fibers in the corpus callosum. Neural Regen Res 2012;7:41-45

21. Ochsenbein-Kölble N, Bilic G, Hall H, Huch R, Zimmermann R. Inducing proliferation of human amnion epithelial and mesenchymal cells for prospective engineering of membrane repair. J Perinat Med 2003;31:287-294

22. Saito S, Yokoyama K, Tamagawa T, Ishiwata I. Derivation and induction of the differentiation of animal ES cells as well as human pluripotent stem cells derived from fetal membrane. Hum Cell 2005;18:135-141

23. Jiawen S, Jianjun Z, Jiewen D, Dedong Y, Hongbo Y, Jun S, Xudong W, Shen SG, Lihe G. Osteogenic differentiation of human amniotic epithelial cells and its application in alveolar defect restoration. Stem Cells Transl Med 2014;3: 1504-1513

24. Murphy S, Rosli S, Acharya R, Mathias L, Lim R, Wallace 
E, Jenkin G. Amnion epithelial cell isolation and characterization for clinical use. Curr Protoc Stem Cell Biol 2010; Chapter 1:Unit 1E.6

25. Díaz-Prado S, Muiños-López E, Hermida-Gómez T, Rendal-Vázquez ME, Fuentes-Boquete I, de Toro FJ, Blanco FJ. Multilineage differentiation potential of cells isolated from the human amniotic membrane. J Cell Biochem 2010;111:846-857

26. Stadler G, Hennerbichler S, Lindenmair A, Peterbauer A,
Hofer K, van Griensven M, Gabriel C, Redl H, Wolbank S. Phenotypic shift of human amniotic epithelial cells in culture is associated with reduced osteogenic differentiation in vitro. Cytotherapy 2008;10:743-752

27. Ilancheran S, Michalska A, Peh G, Wallace EM, Pera M, Manuelpillai U. Stem cells derived from human fetal membranes display multilineage differentiation potential. Biol Reprod 2007;77:577-588 